\title{
Augmented Heat Transfer Techniques in Laminar Flow
}

\author{
Sanath Kumar, Padmini BV, Pradeep LC, R. Seetharamiah
}

\begin{abstract}
This article presents a brief review of various methodologies applied for heat transfer enhancement in laminar flow convection regime. Experimental setup for laminar flow convection heat transfer enhancement using insertions has been explained along with the associated results. Nusselt's number is found to be a key parameter for investigation in order to perceive the enhancement in heat transfer. Similarly, the magnetohydrodynamic mixed convection heat transfer enhancement technique has also been explored. The results of isotherms and fluid flow parameters are discussed which directly affect the heat transfer coefficient. This review article complements the literature in related field and thus will be helpful in order to carry out further experiments in heat transfer enhancement in future.
\end{abstract}

Index Terms - Heat transfer, laminar flow, magnetohydrodynamic, Nusselt's number.

\section{INTRODUCTION}

Heat transfer is a subject that deals with the exchange of thermal energy between two physical bodies or systems. Heat transfer can be classified into various mechanisms like conduction, convection, radiation and phase change or evaporation.

Heat transfer enhancement has become a key focus point in today's field of engineering. Heat transfer enhancement has a widespread application in power plants, automobile, air conditioning industries, food, chemical and pharmaceutical industries to name a few. In the present world, researchers are trying to explore a lot of different fields associated with thermal or heat management [1-3], energy saving as well as alternative fuels [4-7] and safe fuels [8-10] for propulsion. All of these researches have contributed in one way or the other in saving energy. In the current work, we are going to focus more into the heat transfer enhancement and thermal management aspect of energy savings.

Various methods have been tried to enhance heat transfer. Sarma et al. [11] presented a new method to predict heat transfer coefficients with twisted tape inserts in a tube in which the wall-shear and temperature-gradients are properly modified through friction correlation leading to heat transfer augmentation from the tube wall. Ahmed et al. [12] has presented the numerical studies on heat transfer and pressure drop characteristics of copper-water nano-fluid flow through isothermally heated corrugated channels. Very recently, Manglik and Bergles [13, 14] have presented comprehensively their analysis in part $1 \& 2$. Their studies are devoted respectively to the heat transfer and pressure drop correlations for laminar and turbulent regimes with twisted tapes. Several works have reported on the thermal hydraulic characteristics of twisted tapes in laminar flow
[13, 15]. Static mixers [16] and displaced elements [17] have also been considered as suitable for tube-side enhancement through early turbulence promotion.

This paper includes a synopsis of some of the heat transfer enhancement techniques.

\section{HEAT TRANSFER ENHANCEMENT}

A. Heat transfer enhancement in laminar flow through circular tube using combined wire coil and wavy strip with central clearance

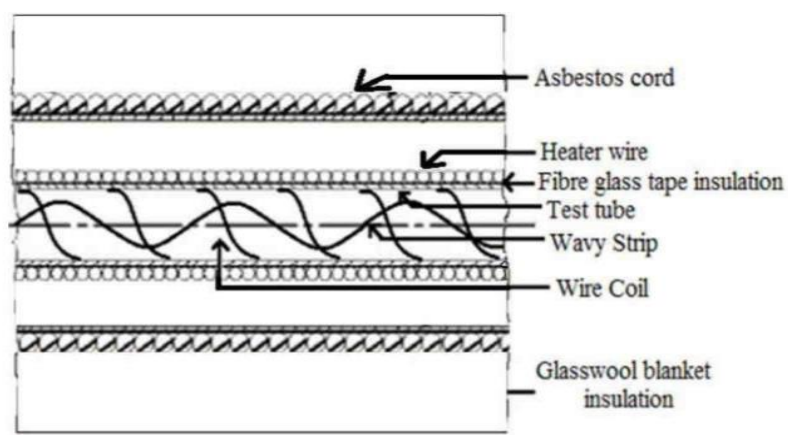

SFig.1: Longitudinal Cross Section of the test section [18]

The experimental setup consists of Vane pump, accumulator, rotameters, mixing chambers, heat transfer exchanger and other sections, the functions of which are already explained by Deb and Poudel [18].

Fig 1 shows the longitudinal cross section of the test section. The duct of the test section is first wrapped up with glass fiber tape, upon which nichrome heater wire with porcelain beads on them are wound. After that, it gets wrapped up by asbestos rope cover and a glass wool which minimizes the loss of heat outside. Finally, the test section is wrapped by a jute bag to keep the insulation in its place.

The variation of temperature and other parameters are discussed in the results.

i. Axial variation of the temperature of the fluid in fig $2,3 \& 4$ shows the increment in bulk mean temperature for varying Reynolds and Prandtl number.

ii. Axial variation of the inner wall temperature is shown by the plots in fig $5,6 \& 7$.

iii. Variation of the Nusselt number in the axial direction for various Reynolds number and Prandtl number are shown in fig $8,9 \& 10$.

Variation of friction factor with Reynolds number in fig 11 
depicts that as Reynolds number increases friction factor also increases.

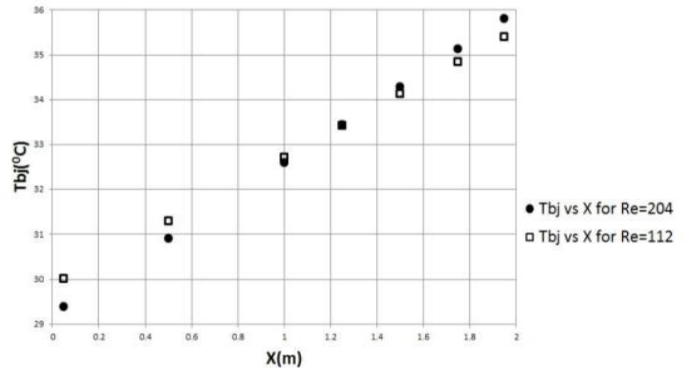

Fig. 2: Bulk mean temperature at particular section $\mathrm{Tb}_{\mathrm{j}}$ in the axial direction $\mathrm{X}$ for $\mathrm{Pr}=573$

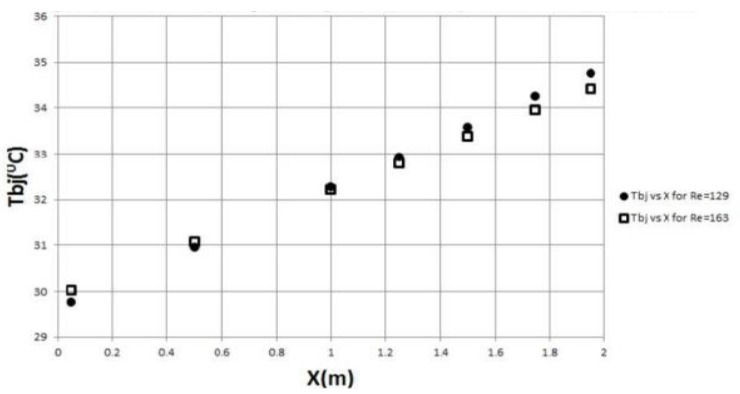

Fig. 3: Bulk mean temperature at particular section $T b_{j}$ in the axial direction $\mathrm{X}$ for $\mathrm{Pr}=582$

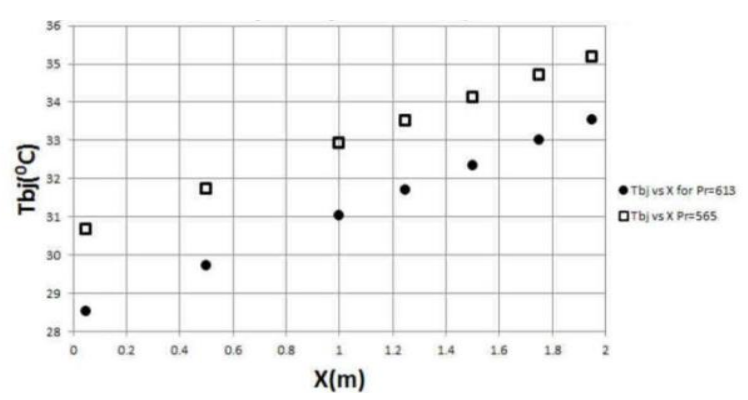

Fig. 4: Bulk mean temperature at particular section $\mathrm{Tb}_{\mathrm{j}}$ in the axial direction $\mathrm{X}$ for $\mathrm{Re}=120$

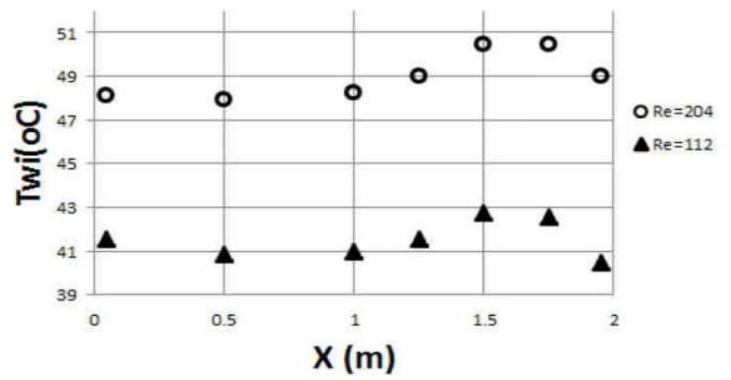

Fig. 5: Inner wall temperature of pipe $\left(\mathrm{Tw}_{\mathrm{i}}\right)$ in the axial direction $\mathrm{X}$ for $\mathrm{Pr}=573$

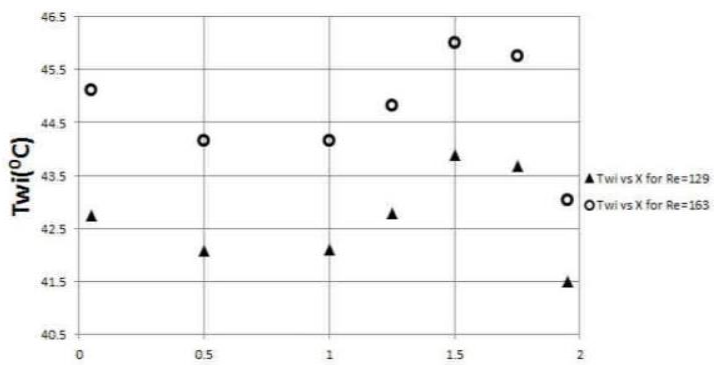

Fig. 6: Inner wall temperature of pipe $\left(\mathrm{Tw}_{\mathrm{i}}\right)$ in the axial direction $\mathrm{X}$ for $\mathrm{Pr}=582$

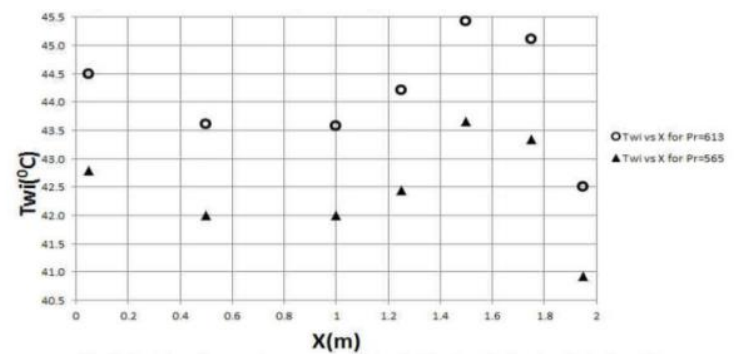

Fig. 7: Inner wall temperature of pipe $\left(\mathrm{Tw}_{\mathrm{i}}\right)$ in the axial direction $\mathrm{X}$ for $\mathrm{Re}=120$

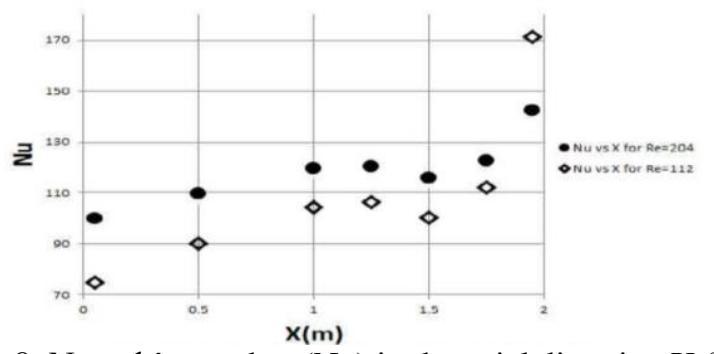

Fig. 8: Nusselt's number $(\mathrm{Nu})$ in the axial direction $\mathrm{X}$ for $\mathrm{Pr}$ $=573$

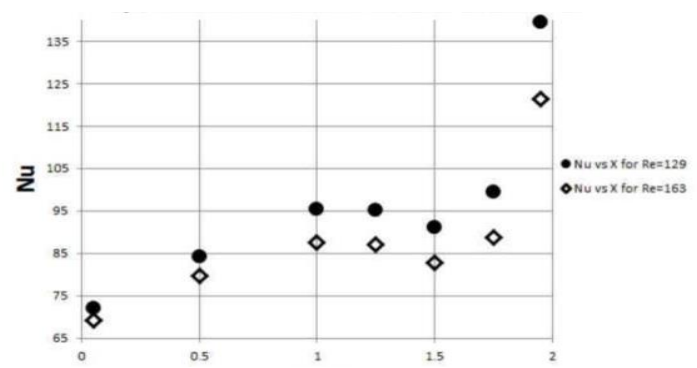

Fig. 9: Nusselt's number $(\mathrm{Nu})$ in the axial direction $\mathrm{X}$ for $\mathrm{Pr}$ $=582$

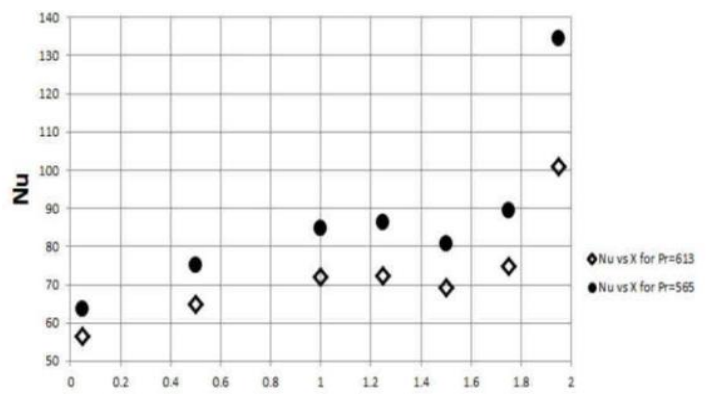

Fig. 10: Nusselt's number $(\mathrm{Nu})$ in the axial direction $X$ for $\operatorname{Re}=120$

B. Numerical Simulation of Hydromagnetic convection in a lid driven cavity containing a heat conducting obstacle with Joule heating

This article by Deb et al. [19-20] discusses the effects of a centrally placed obstacle on the hydromagnetic convection within a lid driven cavity. The model considered is a two dimensional lid driven square enclosure filled with an electrically conducting fluid, i.e., air at $\operatorname{Pr}=0.71$ and having a solid vertical elliptical obstacle that conducts heat at the center. The top and bottom walls are thermally insulated from the surroundings. The left and right walls are at temperatures $T_{c}$ and $T_{h}$ with $T_{c}<T_{h}$. The left wall exhibits translatory motion in the same plane at a velocity $v_{0}$. The other walls are kept stationary. A uniform magnetic field $B_{o}$ 
is applied to the left lid. All the dissipative phenomena except Joule heating are neglected.

The simulations are performed at $\mathrm{Re}=100,0 \leq \mathrm{Ha} \leq 100$ and $\mathrm{Ri}=1$. Fig $11 \& 12$ show the effect of Hartmann number $(\mathrm{Ha})$ on the streamlined and the isotherms for upward and downward motions of the wall.

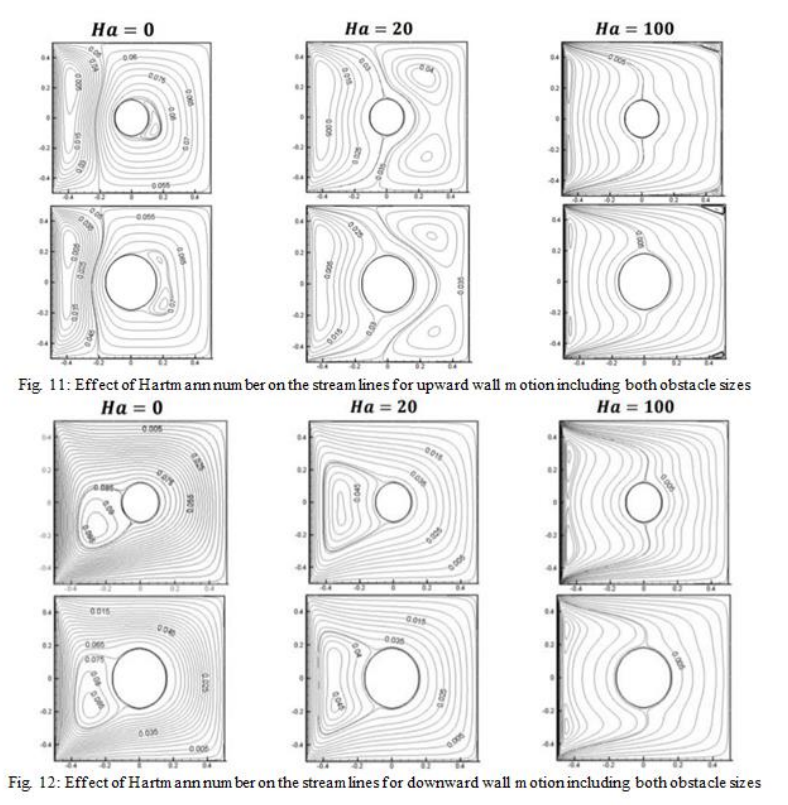

\section{CONCLUSION}

This paper consists of a brief writing on heat transfer enhancement in laminar flow circular tube and by hydromagnetic convection. Heat transfer is a phenomenon that occurs all around us in our daily life. Even though unnoticed, it has a major impact on our lives. Heat transfer is thus a hot topic in today's world with various researches going on in this field.

\section{ACKNOWLEDGMENT}

The authors are grateful to Mr. Sajag Poudel for constant help and support through regular discussions.

\section{REFERENCES}

[1] Arsenyeva, O. P., Tovazhnyansky, L. L., Kapustenko, P. O., \& Khavin, G. L. (2011). Optimal design of plate-and frame heat exchangers for efficient heat recovery in process industries. Energy, 36(8), 4588-4598.

[2] Vasiliev, L. L. (2005). Heat pipes in modern heat exchangers. Applied thermal engineering, 25(1), 1-19.

[3] Sunden, B. (2005, September). High temperature heat exchangers (HTHE). In Proceedings of the 5th International Conference on Science, Engineering and Technology, VIT University, Vellore, India.

[4] Balat, M. (2005). Current alternative engine fuels. Energy Sources, 27(6), 569-577

[5] Murugesan, A., Umarani, C., Subramanian, R., \& Nedunchezhian, N. (2009). Bio-diesel as an alternative fuel for diesel engines - a review. Renewable and sustainable energy reviews, 13(3), 653-662.

[6] Poudel, S., \& Deb, D. Study of Modified Internal Combustion Engine to Run with Ethanol. International Journal of Engineering and Applied Sciences, 4(8).

[7] Gupta, K. K., Rehman, A., \& Sarvaiya, R. M. (2010). Biofuels for the gas turbine: A review. Renewable and Sustainable Energy Reviews, 14(9), 2946-2955.
[8] Babrauskas, V. (2006). Effective heat of combustion for flaming combustion of conifers. Canadian Journal of Forest Research, 36(3), 659-663.

[9] Cartellieri, W., Chmela, F. G., Kapus, P. E., \& Tatschl, R. M. (1994). Mechanisms leading to stable and efficient combustion in lean burn gas engines. In Proceedings of International Symposium COMODIA.

[10] Singh, S. (2001). U.S. Patent No. 6,237,579. Washington, DC: U.S. Patent and Trademark Office.

[11] Sarma, P. K., Subramanyam, T., Kishore, P. S., Rao, V. D., \& Kakac, S. (2003). Laminar convective heat transfer with twisted tape inserts in a tube. International Journal of Thermal Sciences, 42(9), 821-828.

[12] Ahmed, M. A., Shuaib, N. H., Yusoff, M. Z., \& Al-Falahi, A. H. (2011). Numerical investigations of flow and heat transfer enhancement in a corrugated channel using nanofluid. International Communications in Heat and Mass Transfer, 38(10), 1368-1375.

[13] Manglik, R. M., \& Bergles, A. E. (1993). Heat transfer and pressure drop correlations for twisted-tape inserts in isothermal tubes: part Ilaminar flows.

[14] Manglik, R. M., \& Bergles, A. E. (1993). Heat transfer and pressure drop correlations for twisted-tape inserts in isothermal tubes: Part IITransition and turbulent flows. Journal of Heat Transfer, 115(4), 890896.

[15] Wang, L., \& Sunden, B. (2002). Performance comparison of some tube inserts. International Communications in Heat and Mass Transfer, 29(1), 45-56.

[16] Thakur, R. K., Vial, C., Nigam, K. D. P., Nauman, E. B., \& Djelveh, G. (2003). Static mixers in the process industries-a review. Chemical engineering research and design, 81(7), 787-826.

[17] Evans, L. B. (1962). The effect of axial turbulence promoters on heat transfer and pressure drop inside a tube.

[18] Deb, D., \& Poudel, S. Investigation of Heat Transfer Laminar Flow through Circ Combined Wire Coil and Wa.

[19] Dipan Deb, Sajag Poudel, Abhishek Chakrabarti, 2017, Numerical Simulation of Hydromagnetic Convection in a Lid-driven Cavity Containing a Heat Conducting Elliptical Obstacle with Joule Heating, INTERNATIONAL JOURNAL OF ENGINEERING RESEARCH \& TECHNOLOGY (IJERT) Volume 06, Issue 08 (August 2017)

[20] Dipan Deb, Sajag Poudel, Abhishek Chakrabarti, 2017, Numerical Simulation of Hydromagnetic Convection in a Lid-driven Cavity Containing a Heat Conducting Inclined Elliptical Obstacle with Joule Heating, INTERNATIONAL JOURNAL OF ENGINEERING RESEARCH \& TECHNOLOGY (IJERT) Volume 06, Issue 10 (October 2017). 